\title{
Rapid coral reef assessment using 3D modelling and acoustics: Acoustic indices correlate to fish abundance, diversity and environmental indicators in West Papua, Indonesia
}

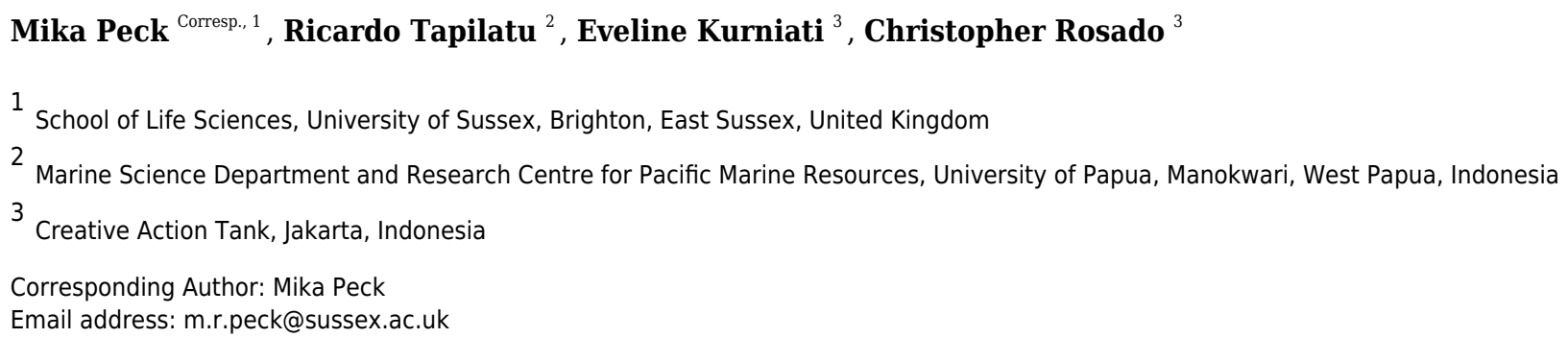

Background. Providing coral reef systems with the greatest chance of survival requires effective assessment and monitoring to guide management at a range of scales from community to government. The development of rapid monitoring approaches amenable to collection at community level, yet recognised by policymakers, remains a challenge. Technologies can increase the scope of data collection. Two promising visual and audio approaches are i) 3D habitat models, generated through photogrammetry from video footage, providing assessment of coral cover structural metrics and ii) audio, from which acoustic indices shown to correlate to vertebrate and invertebrate diversity, can be extracted. Methods. We collected audio and video imagery using low cost underwater cameras (GoPro Hero7 ${ }^{\mathrm{TM}}$ ) from 34 reef samples from West Papua (Indonesia). Using photogrammetry one camera was used to generate 3D models of $4 \mathrm{~m}^{2}$ reef, the other was used to estimate fish abundance and collect audio to generate acoustic indices. We investigated relationships between acoustic metrics, fish abundance/diversity/functional groups, live coral cover and reef structural metrics. Results. Generalized linear modelling (GLM) identified significant but weak correlations between live coral cover and structural metrics extracted from 3D models and stronger relationships between live coral and fish abundance. Acoustic indices correlated to fish abundance, species richness and reef functional metrics associated with overfishing and algal control. Acoustic Evenness (1200 $11000 \mathrm{~Hz})$ and Root Mean Square RMS $(100-1200 \mathrm{~Hz})$ were the best individual predictors overall suggesting traditional bioacoustic indices, providing information on sound energy and the variability in sound levels in specific frequency bands, can contribute to reef assessment. Conclusion. Acoustics and 3D modelling contribute to low-cost, rapid reef 
assessment tools, amenable to community-level data collection, and generate information for coral reef management. Future work should explore whether 3D models of standardised transects and acoustic indices generated from low cost underwater cameras can replicate or support 'gold standard' reef assessment methodologies recognised by policy makers in marine management. 
1 Rapid coral reef assessment using 3D modelling and acoustics: Acoustic indices correlate to 2 fish abundance, diversity and environmental indicators in West Papua, Indonesia.

3

4 Mika Peck $^{1}$, Ricardo Tapilatu ${ }^{2}$, Eveline Kurniati $^{3}$, Christopher Rosado $^{3}$

5

$6{ }^{1}$ School of Life Sciences, University of Sussex, Brighton, East Sussex, UK.

$7 \quad{ }^{2}$ Marine Science Department and Research Centre for Pacific Marine Resources, University of 8 Papua, Manokwari, Indonesia.

$9{ }^{3}$ Creative Action Tank (CAT), Indonesia.

13 Corresponding Author:

14 Mika Peck ${ }^{1}$

15 JMS 5D24, Department of Life Sciences, University of Sussex, Falmer, Brighton BN19QJ, UK 16 Email address: m.r.peck@sussex.ac.uk 


\section{Abstract}

18 Background. Providing coral reef systems with the greatest chance of survival requires effective assessment and monitoring to guide management at a range of scales from community to government. The development of rapid monitoring approaches amenable to collection at community level, yet recognised by policymakers, remains a challenge. Technologies can increase the scope of data collection. Two promising visual and audio approaches are i) 3D habitat models, generated through photogrammetry from video footage, providing assessment of coral cover structural metrics and ii) audio, from which acoustic indices shown to correlate to vertebrate and invertebrate diversity, can be extracted.

Methods. We collected audio and video imagery using low cost underwater cameras (GoPro Hero $7^{\mathrm{TM}}$ ) from 34 reef samples from West Papua (Indonesia). Using photogrammetry one camera was used to generate $3 \mathrm{D}$ models of $4 \mathrm{~m}^{2}$ reef, the other was used to estimate fish abundance and collect audio to generate acoustic indices. We investigated relationships between acoustic metrics, fish abundance/diversity/functional groups, live coral cover and reef structural metrics.

Results. Generalized linear modelling (GLM) identified significant but weak correlations between live coral cover and structural metrics extracted from 3D models and stronger relationships between live coral and fish abundance. Acoustic indices correlated to fish abundance, species richness and reef functional metrics associated with overfishing and algal control. Acoustic Evenness $(1200-11000 \mathrm{~Hz})$ and Root Mean Square RMS $(100-1200 \mathrm{~Hz})$ were the best individual predictors overall suggesting traditional bioacoustic indices, providing information on sound energy and the variability in sound levels in specific frequency bands, can contribute to reef assessment.

Conclusion. Acoustics and 3D modelling contribute to low-cost, rapid reef assessment tools, 44 amenable to community-level data collection, and generate information for coral reef management. Future work should explore whether 3D models of standardised transects and acoustic indices generated from low cost underwater cameras can replicate or support 'gold

47 standard' reef assessment methodologies recognised by policy makers in marine management. 


\section{Introduction}

49 Indonesia's coral reefs support exceptional biodiversity, providing food security and other 50 important ecosystem services to many millions of people (FAO, 2018). Coral reefs face increasing 51 anthropogenic threat, with loss of 23\% of Indonesian corals between 1999 and 2011 (Carter, 52 2018a). Of remaining reefs, a third are considered 'good to excellent condition' with the remainder 53 suffering various levels of anthropogenic degradation. The Birds Head Peninsula (BHP) of West 54 Papua and its reef ecosystems are recognised as the global epicentre of marine diversity, but a lack 55 of resources and information currently limits evidence-based conservation action to address 56 degradation of its reef ecosystems (Carter, 2018b). More optimistically, recent modelling identifies 57 Indonesian reef systems of West Papua as belonging to 50 'bioclimatic reef units' having the 58 highest probability of surviving bleaching impacts from predicted climate change (Beyer et al., 59 2018) that could cause loss of over $90 \%$ of global reefs (Frieler et al., 2013).

61 The key to providing Indonesia's reefs, and the populations dependent on them, the greatest chance 62 of adaptation to climate change is by reducing proximate anthropogenic pressures (Hughes et al., 63 2017). These include overfishing, illegal and destructive harvest, habitat extraction, uncontrolled 64 tourism and marine pollution. Effective management requires assessment, engagement and 65 monitoring to determine impact of interventions, however the development of monitoring 66 approaches amenable to collection at community level, yet recognised by policymakers, remains 67 a challenge. Technologies can increase the scope of data collection in marine environments (Obura 68 et al., 2019), but often require specialist training and equipment. Two promising visual and audio 69 approaches amenable to rapid and community-level data collection for coral reef monitoring 70 include i) habitat metrics, such as rugosity, extracted from 3D models generated by 71 photogrammetry (Structure from Motion SfM) (Young et al., 2017; Burns et al., 2019) and ii) use 72 of acoustic indices as a proxy for vertebrate and invertebrate diversity (Bertucci et al., 2016; 73 Bohnenstiehl et al., 2018; Bolgan et al., 2018; Obura et al., 2019; Elise et al., 2019c; Davies et al., 74 2020).

76 Structural metrics, such as rugosity, provide a measure of physical complexity that underpins reef 77 fish diversity and abundance (Gratwicke \& Speight, 2005; Alvarez-Filip et al., 2009; Raoult et al., 78 2016; Darling et al., 2017). The principal method used by reef scientists to measure structural 
79 complexity is the chain-and-tape method, which produces a measure of rugosity calculated as the 80 ratio of contour-following vs. straight distance between two points on the reef - resulting in the 81 rugosity index ranging from 1 for a flat reef to rarely greater than 3 (Alvarez-Filip et al., 2009).

82 Recently photogrammetry imagery captured using underwater video of reef and rendered into a 83 3D models has allowed estimation of chain-and-tape rugosity and opened the opportunity for more 84 complex measures of habitat structure, such as fractal dimension and vector dispersion, also shown to correlate to fish diversity (Storlazzi et al., 2016; Young et al., 2017; Fukunaga et al., 2019). These new methodologies, in addition to providing datasets for more complex studies of structure (Burns et al., 2019), provide the potential for archiving long-term repositories of 3D images of structure and coral diversity to provide habitat baselines for monitoring to guide management action or restoration activities (Fukunaga et al., 2019).

90

With habitat structure and coral cover/diversity information captured visually, acoustics can contribute by providing a proxy measurement for both diversity and function (Elise et al., 2019c). The coral reef environment has a unique soundscape (Lobel, Kaatz \& Rice, 2010) generated by marine organisms relying on sound for a range of activities including navigation, spawning, feeding, mating, and avoiding predators (Amorim, 2006; Tricas \& Boyle, 2014). Many reef fish species are known to produce sounds to attract mates, warn of danger, scare competitors and predators and maintain social cohesion (Mann \& Lobel, 1995; Tricas \& Boyle, 2014). The characteristic crackling sound of reefs is thought to reflect snapping shrimp (Family Alpheidae) that create broadband, high frequency, snaps in conspecific territorial interactions and feeding (Versluis et al., 2000). Acoustic indices are mutimetrics that allow the quick screening of complex acoustic data as prior knowledge of the composition of the acoustic community is not required - unlike automated analysis based on sound type detection and recognition requiring previous knowledge of targeted signals (Vieira et al., 2015), and time consuming manual analyses that require high levels of expertise. Some previous studies have shown promise, with correlations between acoustic indices and live coral cover (Bertucci et al., 2016; Kaplan et al., 2018; Elise et al., 2019b), fish abundance and diversity (Kennedy et al., 2010; Bertucci et al., 2016; Staaterman et al., 2017; Kaplan et al., 2018). Even relatively simple acoustic descriptors, such as the root-mean-square (RMS) of raw audio signal data have been shown to correlate well with percentage of living coral cover in tropical reefs suggesting the 
110 potential for development of low-cost acoustic habitat assessment tools for coral reef

111 environments (Bertucci et al., 2016). Acoustic monitoring could provide a cost-effective means

112 to remotely assess the community and even functional characteristics of specific marine habitats

113 (Elise et al., 2019b) although care is needed at the different stages of their implementation to

114 clearly understand what the metrics are responding to (Bolgan et al., 2018).

115

116 In this study we collected visual and acoustic data from the West Papuan Reef systems of Raja

117 Ampat and Manokwari to address the following specific question; do habitat metrics and

118 acoustic indices, extracted from underwater audio and video, correlate to coral cover, fish

119 diversity and functional measures of ecological status?

120

\section{Materials \& Methods}

122 Sampling took place from 10 reef sites in Raja Ampat (Waisal S $0^{\circ} 26.417^{\prime}$, E 130 44.418', 4

123 replicates; Batu Lima S0 27.010' E 130 41.807', 2 replicates; Yenros S0 27.624'S E 130 ${ }^{\circ}$

124 41.451' 1 replicate; Sawanare S0 $35.418^{\prime}$ E130 36.209', 8 replicates; Yengkawe S0 $0^{\circ} 25.863^{\prime} \mathrm{E}$

$125130^{\circ} 43.175^{\prime}, 5$ replicates) and Manokwari (Lemon Island S0 ${ }^{\circ} 53.317^{\prime}$ E $134^{\circ} 4.714^{\prime}, 4$

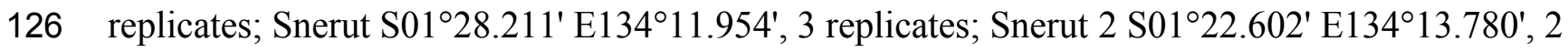

127 replicates; South Manokwari harbour S01²0.892' E 134²16.078'; 2 replicates; Pintu Angin

$128 \mathrm{~S} 01^{\circ} 43.130^{\prime} \mathrm{E} 134^{\circ} 05.046^{\prime}, 3$ replicates) under Indonesian government RISTEKDIKTI permit

129 346/E5/E5.4/SIP/2019 (Figure 1). All of 34 individual replicates were collected by the two same

130 SCUBA divers (Peck/Rosado) representing reef from 3 to $8 \mathrm{~m}$ depth between the times of $9 \mathrm{am}$

131 and $4 \mathrm{pm}$ (Elise et al., 2019a). Following random choice of the initial quadrat at a site, subsequent

132 replicates were generated at distances of $10 \mathrm{~m}$ at the same depth contour. For each $2 \mathrm{~m} \times 2 \mathrm{~m}$

133 replicate, video was filmed in a 'lawnmower pattern' using a GoPro Hero $7^{\mathrm{TM}}$ with a calibration

134 object (Extended 2m tape measure) included in imagery, as described by Young et al. (2017).

135 The camera was set to $1920 \times 1080$ resolution, 30 frames per second and maximum zoom to

136 minimise fisheye effect. Once replicate imagery was collected a second GoPro Hero $7^{\mathrm{TM}}$

137 camera, mounted to a weight and set to default fish-eye, was placed in a corner of the quadrat

138 pointed seaward to capture video of fish communities and record audio over a 10-minute period

139 as both SCUBA divers moved at least $10 \mathrm{~m}$ away to avoid disturbance to recordings and fish. 
141 Generation of 3D models followed protocol in Young et al. (2017). In summary, raw video

142 footage was first converted to overlapping image sequences every 10 frames ( $3 \mathrm{fps}$ ) using free

143 software FFmpeg (www.ffmpeg.org) for import to Agisoft Metashape

144 (https://www.agisoft.com/). The model was rendered into 3D imagery then exported as a

145 wavefront (.obj) file for analysis using Rhinoceros (https://www.rhino3d.com/) and extraction of

146 rugosity metrics, rugosity, vector dispersion and fractal dimension (Young et al., 2017).

147 Overhead images of the reef transect were exported from Agisoft Metashape as jpeg files for

148 estimation of percentage live coral cover in ImageJ (https://imagej.nih.gov/ij/). Total abundance

149 of fish, abundance of fish estimated at $>30 \mathrm{~cm}$ and fish species richness was estimated by an 150 experienced ichthyologist (author EK) from video from 5 to 6 minutes (this was chosen as it 151 allows time for fish to settle after camera placement and divers to retreat to avoid acoustic 152 interference). Coral health was assessed by the number of Chaetodontidae (Butterflyfish), fishing 153 pressure estimated by summing counts of Serranidae (Groupers), Lutjanidae (Snapper)

154 Lethrinidae (Emperors) and Haemulidae (Grunts), with a measure of Algal control provided by a 155 count of Scaridae (Parrotfish), Acathuridae (Surgeonfishes, tangs, unicornfish) and Siganidae 156 (Rabbitfish) (Giyanto et al., 2017). Motor noise from each minute of video sampled was also 157 reported as present or absent.

158

159 Audio was extracted from videos using Audacity software (https://www.audacityteam.org/) and 160 saved as WAV files (Stereo, project rate 48,000 Hz, 32-bit float) for further analysis. Two 161 approaches to acoustic analysis were undertaken. The first applies generalized linear modelling 162 (GLM) to investigate relationships between fish diversity metrics, live coral cover, structural 163 complexity (rugosity and vector dispersion) and acoustic indices. The Soundecology package 164 (multiple_sounds; Villanueva-Rivera \& Pijanowski, 2018) was used to extract acoustic indices 165 from audio (minutes 4 to 5, 5 to 6, 6 to 7) for two frequency ranges. A lower band representing 166 'fish' audio of $100 \mathrm{hz}-1200 \mathrm{~Hz}(100 \mathrm{~Hz}$ bins $)$ unless otherwise stated, and a higher frequency 167 range, $1200 \mathrm{~Hz}-11000 \mathrm{~Hz}(1000 \mathrm{~Hz}$ bins), representing 'invertebrates' (Patrick Lyon et al., 168 2019). Acoustic Complexity Index (ACI; FFT window $=512$, cluster size $=5 \mathrm{~s}$, left hand channel) (Pieretti, Farina \& Morri, 2011) Acoustic Diversity Index (ADI; bin frequency step = $100 \mathrm{~Hz}, 0-1200 \mathrm{~Hz} / 1200-11000 \mathrm{~Hz}$, left channel) (Villanueva-Rivera et al., 2011), Acoustic

171 Evenness Index (AEI db threshold $-50 \mathrm{db}$, frequency step $=100$ for $0-1200 \mathrm{~Hz}$, frequency step 
$172=1000 \mathrm{~Hz}$ for $1200-11050 \mathrm{~Hz}$ ) (Villanueva-Rivera et al., 2011) and Bioacoustic Index (BI; FFT

173 window $=512$, left channel) (Boelman et al., 2007) were calculated for the left channel and both

174 frequency ranges). Root Mean Square (RMS) and Roughness were calculated for each frequency

175 band using R package seewave (Sueur, Aubin \& Simonis, 2008). Ratios (Acoustic index at low

176 frequency range $100 \mathrm{hz}-1200 \mathrm{~Hz}$ / acoustic index at frequency range $1200 \mathrm{~Hz}-11050 \mathrm{~Hz}$ ) were

177 calculated for amplitude-based indices (RMS, Roughness, ACI, BI) to avoid influence of auto

178 gain in GoPro acoustic recordings extracted from video (Lindseth \& Lobel, 2018). Values for

179 both low and high frequency ranges and ratios were compared for spectral frequency-based

180 indices (ADI, AEI). Temporal stability of acoustic indices was explored using correlation

181 analysis ( $\mathrm{R}$ package vegan).

182

183 Generalised linear models were used to explore relationships between; fish abundance, species

184 richness and fish community indicators against live coral cover (Poisson model), live coral cover

185 and acoustic indices (Binomial model), fish diversity indices and acoustic indices (Poisson

186 models), rugosity and acoustic indices (Gaussian) and vector dispersion and acoustic indices

187 (Gaussian). Models were visually checked for normality and homoscedasticity of residuals.

188 Model selection was applied to identify meaningful relationships based on Akaike's Information

189 Criterion (AIC), with 'percentage deviance explained' (1-deviance/null model deviance)

190 reported.

191

192 The second approach investigated covariate relationships with mean frequency spectrum for each 193 audio sample. Distance based redundancy analysis (db-RDA) was applied to the cumulative 194 spectral dissimilarity matrix of the mean frequency spectra (Lellouch et al., 2014) (FFT Hanning 195 window $=512$, left channel) for both the lower frequency range $(100-1200 \mathrm{~Hz})$ and higher 196 range $(1200-11050 \mathrm{~Hz})$, following Sueur (2018), with Monte Carlo testing for significance of 197 covariates. All statistical programming was undertaken in RStudio Version 1.2.5033 (RStudio 198 Team, 2015) using R (Version 3.6.2) and code and datasets are available in GitHub at 199 https://github.com/mrp21/West-Papua. The repository also contains links to sample audio and 200 video.

201

202 


\section{Results}

204 Extraction of acoustic indices was successful for all replicates, with rendering of 3D imagery and

205 extraction of subsequent rugosity measures successful in 31/34 replicates (Figure 2).

206

207 A significant positive relationship $\left(\mathrm{Z}_{30,29}=50.82, \mathrm{p}<0.0001\right)$, showing an increase in fish

208 abundance with an increase in live coral cover, is observed for the GLM Poisson model of fish 209 abundance count data against proportion of live coral cover, accounting for $47.2 \%$ of deviance

210 (Figure 3). All other diversity metrics for fish are non-significant ( $p>0.05)$ in relation to live 211 coral cover. Rugosity $\left(Z_{30,29}=13.54, p<0.0001\right)$ and Vector dispersion $\left(Z_{29,28}=-4.27, p<0.0001\right)$ 212 are statistically significant but only explain $3.4 \%$ and $0.3 \%$ of variability in live coral cover 213 respectively.

214

215 Temporal stability across replicates for acoustic indices extracted from minutes 4 to 5,5 to 6 and 2166 to 7 is shown in Figure 4 (Supplementary information, S1), with eight of the acoustic indices 217 showing temporal correlation coefficients of over 0.7 . The stability of metrics ranged from a high 218 correlation coefficient of 0.95 for Acoustic Complexity ratio (ACI Ratio) to 0.37 Acoustic

219 Diversity Ratio (AD ratio). To guide interpretation, the correlation coefficient for fish abundance 220 across this same timescale for all replicates was 0.74 .

221

222 A GLM model including all acoustic indices was not significantly different from a null model in 223 explaining proportional coral cover ( $\left.\operatorname{LHR}_{30,20}=2.74, \mathrm{p}=0.98\right)$. Acoustic indices did not 224 significantly explain rugosity $\left(\mathrm{F}_{30,20}=0.08, \mathrm{p}=0.61\right)$ or vector dispersion $\left(\mathrm{F}_{29,19}=0.02, \mathrm{p}=0.89\right)$, 225 suggesting no direct link between acoustics and structure at the scale of this study.

226

Using all 18 acoustic indices (extracted from minutes 5 to 6; sample spectrograms in Figure 5) to 228 model fish abundance explains $83.4 \%$ of model deviance compared to a null model $\left(\chi^{2} 33,15=\right.$ 229 5999.1, $\mathrm{p}=<0.0001)$. A significant difference between this model and one that includes a marker for motor noise $\left(\chi^{2} 14,15=-91.194, \mathrm{p}=<0.0001\right)$ meant that we removed 7 samples with motor noise to better understand the ability of acoustic indices to respond to marine acoustic environments without obvious anthrophony in all analyses below. Without obvious motor noise the 18 indices significantly explained $89.4 \%$ of model deviance $\left(\chi^{2} 26,8=2875.8, p=<0.0001\right)$. 
234 Forward, backways and bothway covariate selection, using Akaike's Information Criteria (AIC) 235 to select the most parsimonious model, suggests fish abundance can be modeled as effectively 236 (89.4\% deviance explained) as the full model using 16 predictors although differences in AIC 237 between models is small. Significant parsimonious models based on lowest AIC values show that 238 fish species richness is significantly explained by 4 acoustic indices $\left(\chi^{2} 26,8=342.1, \mathrm{p}=<0.0001\right.$; $23938.6 \%$ deviance explained), Fish $>30 \mathrm{~cm}$ length is predicted by 14 acoustic indices $\left(\chi^{2}{ }_{26,8}=\right.$ $240341.5, \mathrm{p}=<0.0001 ; 87.3 \%$ deviance explained), and Fishing pressure is predicted by 4 indices $\left(\chi^{2}\right.$ $24126,8=19.7, \mathrm{p}=0.0005 ; 34.5 \%$ deviance explained). Algal control is best predicted by 16 indices $242\left(\chi^{2} 26,8=116.2, p=<0.0001 ; 81.3 \%\right.$ deviance explained $)$ and Coral Health by 4 indices $\left(\chi^{2} 26,8=\right.$ $24312.9, \mathrm{p}=0.01 ; 27.3 \%$ deviance explained).

244

245 GLM analysis identifies all individual acoustic indices as statistically significant in explaining 246 fish abundance, with deviance explained ranging from $0.2 \%$ to $40 \%$ (Table 1; Supplementary 247 information, S2). The top 3 indices explaining fish abundance are AEI $(1200-11050 \mathrm{~Hz} ; 40 \%$ 248 deviance explained), ACI (100 - $1200 \mathrm{~Hz} ; 38 \%$ deviance explained) and RMS Ratio (33.5\% 249 deviance explained). The top 3 indices predicting fish species richness are AEI (1200 - 11050 $250 \mathrm{~Hz} ; 24 \%$ deviance explained), ADI (1200 - $11050 \mathrm{~Hz}$ 19\% deviance explained) and AEI Ratio 251 (19.2\% deviance explained). For fish over $30 \mathrm{~cm}$ in length the top predictors are ACI (1200 $25211050 \mathrm{~Hz} ; 25.3 \%$ deviance explained), RMS (100 - 1200Hz; $18.3 \%$ deviance explained) and AEI 253 Ratio (17.8\% deviance explained). Fishing Pressure is predicted by a similar set of indices; RMS 254 (100 - 1200Hz; 12\% deviance explained), ACI $(1200-11050 \mathrm{~Hz} ; 10.9 \%$ deviance explained) 255 and AEI (1200 - 11050Hz; 7.3\% deviance explained). Algal control is predicted best by AEI 256 Ratio (22.9\% deviance explained), AEI (1200 - 11050Hz; $21.8 \%$ deviance explained) and RMS $257(100-1200 \mathrm{~Hz} ; 21.7 \%$ deviance explained). Coral Health (Corallivores) was not significantly 258 predicted by any index.

259

260 No single acoustic indicator provides the best prediction for all categories however AEI (1200 $26111050 \mathrm{~Hz}$ ) provides top 3 predictions for 4 dependent variable categories (Abundance, Species 262 richness, Fishing Pressure and Algal Control) and the highest for fish abundance (Figure 6). 263 RMS (100 - $1200 \mathrm{~Hz}$ ) provides top 3 predictions for 3 dependent variable categories (Fish over $26430 \mathrm{~cm}$, Fishing pressure and Algal control), and the highest for indicator of fishing pressure 
265 although it has low explanatory power. All other acoustic indices provide only top 3 predictions 266 for 2 or fewer dependent variable categories (Table 1).

267

268

A correlation plot, for model deviance explained by all acoustic indices across fish abundance,

269

270

271

272

273

274

275

276

277

278

279

280

281

282

283

284

285

286

287

288

289

290

291

292

293

294

295

species richness and reef status indicator categories (Figure 7), shows that good explanatory power for acoustic indices for larger fish (over $30 \mathrm{~cm}$ in length) is positively correlated to indicator species of fishing pressure (Correlation coefficient $0.64 ; p=0.004$ ) and fish abundance (Correlation coefficient $0.56 ; \mathrm{p}=0.01$,). Explanatory power for fish abundance is also significantly correlated to explanatory power for indicator species of coral reef algal control (Correlation coefficient $0.57 ; \mathrm{p}=0.01$ ). Fish species richness, explained by acoustic indices, is correlated with abundance (Correlation coefficient $0.75 ; \mathrm{p}<0.001$ ) and indicator species of coral reef algal control (Correlation coefficient $0.68 ; \mathrm{p}=0.002$ ).

Distance based redundancy analysis show the first axis explains $63 \%$ of projected inertia based on spectral dissimilarity for frequencies $100-1200 \mathrm{~Hz}$ with only site showing significant explanatory power (Monte-Carlo, 1000, $\mathrm{p}<0.001$ ), explaining $72.2 \%$ of inertia. All other locational, structural or fish species richness covariates provide no explanatory power ( $\mathrm{p}>0.05)$. For the higher frequency range $(1200-11050 \mathrm{~Hz})$ a similar pattern is seen with the first axis providing $68 \%$ of projected inertia with only site showing significant predictive power (MonteCarlo, 1000, $\mathrm{p}=0.02$ ) and explaining $54.4 \%$ of inertia. It is worth noting that fish abundance is nearly significant (Monte-Carlo, 1000, p=0.06), explaining 93.3\% of inertia although all other predictors are statistically insignificant.

\section{Discussion}

Effective management of extensive and remote coral reef systems, such as those of the Birds Head Seascape in West Papua, requires engagement with people from local communities in assessment, management and monitoring activities. However, coral reef assessment and monitoring methodologies amenable to data collection at grassroots level are rarely recognised by policymakers, as they can lack methodological and statistical rigour of standard methods (Obura et al., 2019). Development of tools to collect reef status data applicable to citizen, or 
296 civic science projects (Dillon, Stevenson \& Wals, 2016; Schmiedel et al., 2016), yet recognised 297 by policymakers could increase the scope of effective reef management. Technologies can 298 provide the opportunity to increase scope and rigour of data collected, and it is within this 299 context that we investigated the use of relatively low-cost underwater cameras in assessment of 300 coral reef status. We used simple video protocols to collect fish abundance estimates, acoustic 301 records and structural habitat metrics through subsequent photogrammetric 3D reconstruction of 302 reef quadrats (Bertucci et al., 2016; Patrick Lyon et al., 2019). Each individual 10-minute 303 replicate could be collected by 2 people in approximately 15 minutes, an important consideration 304 if using SCUBA equipment that limits dive times. Estimation of abundance and species richness 305 306 307 308 of fish from video footage does, however, require time and expertise in fish identification and good consistent placement of cameras to ensure similar field of views are available for analysis. The extraction of 3D models also requires technical skill, access to computers and time, as does the extraction of audio and analysis of acoustic indices, although future development of apps could minimise the technical burden on users. To our knowledge this is the first time audio from low-cost cameras has been investigated to support short-term reef assessments, with previous studies requiring simultaneous deployment of separate hydrophone equipment, although it should be noted that the GoPro ${ }^{\mathrm{TM}}$ microphone is not as sensitive or omnidirectional as a dedicated hydrophone, and might underestimate vocal community complexity.

Fish abundance correlated significantly with proportion of hard coral cover reflecting similar correlations between abundance and coral cover in studies carried out at a similar scale

317 (Komyakova, Munday \& Jones, 2013). This relationship highlights the importance of live coral, 318 and its measurement, in reef assessments, although coral structural forms may be more important 319 predictors of functional or biodiversity status (Elise et al., 2019b). With coral playing roles as a 320 food source for corallivores, as shelter from predation and for reproduction for reef fish it is clear that differing coral morphologies support a range of different functional requirements dependent on fish species and life strategies (Komyakova, Munday \& Jones, 2013).

Structural complexity is recognised as an integral component of coral reef ecosystems correlating to total live coral cover, fish density and biomass (Graham \& Nash, 2013), however the strength 
327 Nash, 2013; Komyakova, Munday \& Jones, 2013; Burns et al., 2019). We found a significant but 328 weak correlation between fish abundance and rugosity and vector dispersion metrics extracted 329 from reconstructed 3D imagery of reef (Young et al., 2017), although this may reflect the smaller 330 scale $\left(4 \mathrm{~m}^{2}\right)$ of reef habitat analysed (Fukunaga et al., 2019). Hernández-Landa et al. (2020) 331 suggest $374 \mathrm{~m}^{2}$ as the minimum sampling area to capture $90 \%$ of coral species richness for 332 Caribbean systems with scale likely to play a major role in any analyses of this type. Previous 333 studies have shown a lack of correlation between coral cover and structural complexity when 334 coral cover is lower (Graham et al., 2009) and this may have weakened relationships in our 335 study. Although total coral cover is often associated with greater structural complexity, Burns et 336 al. (2019) show that different morphological types, i.e. branching Acropora and Porites corals, 337 influence complexity in different ways suggesting future work should aim to better understand 338 relationships between structural complexity and function at the level of coral genera/ typology. It 339 is, however, clear that reef degradation from tropical storms, bleaching events and declines in 340 herbivores are associated with structural simplification (Alvarez-Filip et al., 2009), and influence 341 structure of fish assemblages, making measurement of structural complexity a vital component 342 of reef assessment protocols (Fukunaga et al., 2019). Photogrammetric techniques using low cost 343 cameras do provide the opportunity for long-term archiving of 3D reef imagery and monitoring 344 of structural degradation or recovery (Graham \& Nash, 2013; Obura et al., 2019) whilst 345 providing datasets for further investigation.

346

347 Differences in mean spectra for both the low frequency range and high frequency range between 348 sites using the $\beta$ index, spectral dissimilarity (Sueur, 2018), could not be explained by any of the 349 explanatory variables. Mean spectral values are calculated in the frequency domain and scaled to 350 cumulative distribution functions in the comparison, so should be comparable across sites, even 351 with variable gain measurements applied across samples. Our lack of correlation likely reflects

352 the complexities of comparing frequency distributions even when dividing spectra into more 353 meaningful ranges, as in our study, and could still show promise with further refinement.

355 The influence of habitat structure on soundscape has been seen in other work (Freeman et al., 356 2018; Elise et al., 2019b), suggesting that structurally complex environments accommodate 357 higher diversity of soniferous fish species generating low frequency sounds. In our study we did 
358

359

360

361

362

363

364

365

366

367

368

369

370

371

372

373

374

375

376

377

378

379

380

381

382

383

384

385

386

387

388

not find a significant correlation between acoustic indices and structural measures, rugosity and vector dispersal, extracted from photogrammetry. This may reflect the scale of our study that focused on smaller $4 \mathrm{~m}^{2}$ reef images that may not represent the broader soundscape or habitat complexity. Elise et al. (2019b) also suggest care needs to be taken to disentangle low frequency acoustic signals generated locally from sounds reflected by hard reef structures generated at a distance that propagate long distances underwater (Lugli, 2012). Although several other studies have found a correlation between acoustic indices and live coral cover (Bertucci et al., 2016; Kaplan et al., 2018; Elise et al., 2019b) we did not find a significant relationship. The relationship between live coral and reef acoustics may be more complex and depend more on coral growth form. It is growth form that generates the habitat structures used by the range of soniferous vertebrate and invertebrate communities (Elise et al., 2019b; Fukunaga et al., 2019).

As with other studies (Kennedy et al., 2010; Bertucci et al., 2016; Staaterman et al., 2017; Kaplan et al., 2018), we observed some of the strongest relationships between acoustic indices and fish abundance. Indices providing explanatory power in our study can be grouped into those that measure aspects of complexity across frequencies (acoustic evenness), time (acoustic complexity) and proxies of energy levels (root mean square).

Measuring differences in frequencies, the index providing best explanatory power of fish abundance and relatively high explanation for fish species richness, fishing pressure and algal control was Acoustic Evenness $(1200-11000 \mathrm{~Hz})$ (Figure 6; Table 1). Acoustic Evenness Indices apply the Gini coefficient (a measure of distribution inequality) to frequency bins over the sampling time period (Villanueva-Rivera et al., 2011). Working in the frequency domain this index should be robust to influence of auto gain functions associated with audio, allowing direct comparison of AEI index values across replicates investigated in this study. According to the literature the higher range AEI values $(1200-11050 \mathrm{~Hz})$ are associated with invertebrate activity (Patrick Lyon et al., 2019) with dominant invertebrate acoustic sound on coral reef environments thought to be generated through cavitation by snapping shrimp (Versluis et al., 2000). This distinctive sound, that peaks between $4-6 \mathrm{kHz}$ (Au \& Banks, 1998), is put to use by Indonesian fishers to identify good fishing grounds above coral reef by placing their ear to a wooden oar lowered into the sea to listen for the 'crackling' sound (Yunaldi Yahya, pers comm). 
389 Lower AEI values represent more even distribution of sound across frequency bins, with values

390 approaching unity representing extreme contributions from one or a few frequency bins

391 (Villanueva-Rivera \& Pijanowski, 2018; Lindseth \& Lobel, 2018). Low Acoustic Evenness in

392 the higher frequency band at low fish abundance suggest more even distribution of sound across

393 frequencies. With increase in fish abundance, greater variability in distribution is observed

394 reflecting sound associated with greater fish vocalizations and/or reflects increasing invertebrate

395 activity, with the index reporting increased 'crackling' associated with reef. This index may be

396 reflecting increasing invertebrate activity that provides a proxy for more pristine ecosystem

397 status with subsequently higher fish abundance, species richness and size.

398

399 Root Mean Square (RMS $100-1200 \mathrm{~Hz}$ ) provides a measure of sound energy within the system 400 and is the best predictor of fishing pressure, i.e. the presence of target species within families

401 Serranidae, Lutjanidae, Lethrinidae and Haemulidae (Giyanto et al., 2017). It also provides

402 relatively good predictive power for fish over $30 \mathrm{~cm}$ in length, and species associated with algal

403 control. The relationship is visualized in figure 5, with more spectral bands and higher intensities

404 contributing to the acoustic environment at sites with higher fish abundance (figure 5A, 5B).

405 Soniferous fish are generally thought to contribute to the soundscape in this lower frequency

406 range (Kennedy et al., 2010; Elise et al., 2019b) and this index could reflect increasing

407 vocalizations from acoustically active fish species at these sites. These results agree with those

408 observed by Kaplan et al. (2018) for Maui reef systems who found correlation between diel SPL

409 (RMS) trends and soniferous fish. Some care should be taken in interpreting higher activity in

410 the lower frequency range however, as although soniferous fish contribute to the soundscape in

411 the lower frequency range (Kennedy et al., 2010; Elise et al., 2019b) this frequency range also

412 registers anthropogenic activity that has been seen to mask biophony (Bolgan et al., 2018). In

413 this study we avoided obvious anthrophony by excluding files with sounds of motors, but it

414 would be useful to develop a measure of anthrophony itself, as it can directly impact on a range

415 of reef biological processes (Simpson et al., 2005; Ruiz et al., 2017; Jain-Schlaepfer et al., 2018),

416 and act as a proxy for other anthropogenic pressures.

417

418 Our results suggesting AEI and RMS as the best predictors of fish abundance reflect the

419 conclusions of Kaplan et al. (2018) that traditional bioacoustic indices providing information on 
420 sound energy and the variability in sound levels in specific frequency bands are easier to 421 understand and more robust than other indices such as acoustic complexity index (ACI). In 422 summary, acoustic indices providing information on both sound complexity (AEI) and energy 423 (RMS) significantly correlate with fish abundance, species richness and family level indicators 424 of ecosystem status potentially contributing to rapid bioassessment toolkits as suggested for 425 terrestrial environments (Eldridge et al., 2018), although further testing and validation is 426 required. It would be important to consider temporal variability of acoustic indices, as they 427 differed significantly between indices investigated and further experimentation and analysis is 428 required to determine what this implies in terms of choosing an optimal coral reef bioassessment 429 acoustic index. Ultimately it is important to clearly define the direct or indirect acoustic linkage between acoustic index response and the ecological metric under investigation and undertake further work to tune and optimize acoustic indices (Bolgan et al., 2018). It should also be noted that diel and longer-term trends in acoustics cannot be captured using the approach outlined here and that future work on rapid acoustic assessment does need to place the measurement of rapid assessment acoustic indices in context of site-specific, longer-term, temporal patterns.

This work provides evidence that acoustic indices can generate information on the ecological status of reef environments. This is best illustrated in figure 7 that summarises the explanatory power of acosustic indices across covariates of fish abundance, species richness, and environmental indicator groups. Good explanatory power of fish abundance correlates well with explanatory power of fish species richness, fish over $30 \mathrm{~cm}$ in length, and species associated with algal control - counts of Scaridae, Acathuridae and Siganidae (Giyanto et al., 2017). Good

442 explanatory power for fish over $30 \mathrm{~cm}$ correlates with species targeted by fishers; Serranidae, 443 Lutjanidae, Lethrinidae and Haemulidae (Giyanto et al., 2017) and explanatory power for fish 444 species richness correlates significantly with species associated with algal control. The results 445 suggest a role for the use of acoustic indices as a measure of fish abundance and reef status as 446 they correlate with multiple acoustic indices, with the best single acoustic index observed to be 447 the Acoustic Evenness Index for the frequency range $1200-11000 \mathrm{~Hz}$.

\section{Conclusions}


450 The data collection process is amenable to community-level application with some training, and 451 would allow use of snorkeling equipment rather than SCUBA, for shallow reef systems. Each 452 sample can be collected quickly (approx. 15 minutes per sample) with imagery providing 453 information on coral cover and coral taxonomic diversity. 3D visual imagery provides the 454 opportunity for long-term archiving of permanent transects and assessment of standard measures 455 of coral cover and diversity and could play an important role in monitoring degradation, and 456 recovery, of reef structures, both natural and artificial (Graham \& Nash, 2013; Darling et al., 457 2017; Fukunaga et al., 2019; Obura et al., 2019). Acoustic indices offer insights to the status of 458 biodiversity and function in reef environments, yet they remain rather blunt instruments. Greater 459 insights might be gained through more advanced analytical approaches such as; sinusoidal 460 modelling encompassing spectro-temporal space (Eldridge et al., 2016), identification of 461 soniferous 'indicator' species of reef status, the development of acoustic taxonomies (Desiderà et 462 al., 2019) and/or linking acoustics more directly to components of reef function (Elise et al., 463 2019d). Future work should also explore whether 3D models of standardised transects and 464 acoustic indices generated from low cost underwater cameras can replicate or support 'gold 465 standard' reef assessment methodologies. This would bridge the current gap between data 466 collected by community-based protocols and standard techniques that feed in to monitoring, 467 management, governance and policymaking.

468

469

\section{Acknowledgements}

We would like to thank the Bupati of South Manokwari, Marcus Waran, and his staff for supporting field surveys in South Manokwari, staff of the University of West Papua, in particular Dimas Algutomo, for supporting the dive operations and Scuba Republic for logistics during reef survey of Raja Ampat. We thank Mohammad Abrar (LIPI, Indonesian Institute of Sciences) for project support and RISTEK for support in attaining the research and training visa (Visa 475 2C11DF0016AT).

476

\section{References}

478 Alvarez-Filip L, Dulvy NK, Côteé IM, Watkinson AR, Gill JA. 2011. Coral identity underpins 479 architectural complexity on Caribbean reefs. Ecological Applications 21:2223-2231. DOI:

$$
10.1890 / 10-1563.1 .
$$


481 Alvarez-Filip L, Dulvy NK, Gill JA, Côté IM, Watkinson AR. 2009. Flattening of Caribbean 482 coral reefs: Region-wide declines in architectural complexity. Proceedings of the Royal 483 Society B: Biological Sciences 276:3019-3025. DOI: 10.1098/rspb.2009.0339.

484 Amorim MCP. 2006. Diversity in sound production in fish. In: Ladich F, Collin SP, Moller P, 485 Kapoor BG eds. Communication in fishes. Enfield: Science Publishers, 71-105.

486 Au WWL, Banks K. 1998. The acoustics of the snapping shrimp Synalpheus parneomeris in 487 Kaneohe Bay. The Journal of the Acoustical Society of America 103:41-47. DOI: $488 \quad 10.1121 / 1.423234$.

489 Bertucci F, Parmentier E, Lecellier G, Hawkins AD, Lecchini D. 2016. Acoustic indices provide 490 information on the status of coral reefs: an example from Moorea Island in the South $491 \quad$ Pacific. Scientific reports 6:33326. DOI: 10.1038/srep33326.

492 Beyer HL, Kennedy E V., Beger M, Chen CA, Cinner JE, Darling ES, Eakin CM, Gates RD, 493 Heron SF, Knowlton N, Obura DO, Palumbi SR, Possingham HP, Puotinen M, Runting 494 495 496 RK, Skirving WJ, Spalding M, Wilson KA, Wood S, Veron JE, Hoegh-Guldberg O. 2018. Risk-sensitive planning for conserving coral reefs under rapid climate change. Conservation Letters:e12587. DOI: 10.1111/conl.12587.

Boelman NT, Asner GP, Hart PJ, Martin RE. 2007. Multi-Trophic Invasion Resistance in Hawaii: Bioacoustics, Field Surveys, and Airborne Remote Sensing. Ecological Applications 17:2137-2144.

Bohnenstiehl DR, Lyon RP, Caretti ON, Ricci SW, Eggleston DB. 2018. Investigating the utility of ecoacoustic metrics in marine soundscapes. Journal of Ecoacoustics 2:1-1. DOI: 10.22261/jea.r11561.

Bolgan M, Amorim MCP, Fonseca PJ, Di Iorio L, Parmentier E. 2018. Acoustic complexity of vocal fish communities: A field and controlled validation. Scientific Reports 8:1-11. DOI: 10.1038/s41598-018-28771-6.

507

Burns JHR, Fukunaga A, Pascoe KH, Runyan A, Craig BK, Talbot J, Pugh A, Kosaki RK. 2019. 3D Habitat Complexity of Coral Reefs in the Northwestern Hawaiian Islands is driven by coral assemblage structure. In: ISPRS Annals of the Photogrammetry, Remote Sensing and Spatial Information Sciences. Copernicus GmbH, 61-67. DOI: 10.5194/isprs-archivesXLII-2-W10-61-2019.

Carter E. 2018a. State of the Sea: Indonesia, Volume One: An Overview of Marine Resource 
512

513

514

515

516

517

518

519

520

521

522

523

524

525

526

527

528

529

530

531

532

533

534

535

536

537

538

539

540

541

542

Management for Small-Scale Fisheries and Critical Marine Habitats in Indonesia. Jakarta: Ministry of Marine A_airs and Fisheries (MMAF), Republic of Indonesia and USAID Sustainable Project, Ecosystems Advanced (SEA).

Carter E. 2018b. State of the Sea: Indonesia, Volume Two: Introducing the Heart of the Eastern Indonesia Seas: Status and USAID SEA Project Support. Jakarta: Ministry of Marine A_airs and Fisheries (MMAF), Republic of Indonesia and USAID Sustainable Ecosystems Advanced (SEA) Project (2018).

Darling ES, Graham NAJ, Januchowski-Hartley FA, Nash KL, Pratchett MS, Wilson SK. 2017. Relationships between structural complexity, coral traits, and reef fish assemblages. Coral Reefs 36:561-575. DOI: 10.1007/s00338-017-1539-z.

Davies BFR, Attrill MJ, Holmes L, Rees A, Witt MJ, Sheehan E V. 2020. Acoustic Complexity Index to assess benthic biodiversity of a partially protected area in the southwest of the UK. Ecological Indicators 111:106019. DOI: 10.1016/j.ecolind.2019.106019.

Desiderà E, Guidetti P, Panzalis P, Navone A, Valentini-Poirrier CA, Boissery P, Gervaise C, Iorio L Di. 2019. Acoustic fish communities: Sound diversity of rocky habitats reflects fish species diversity. Marine Ecology Progress Series 608:183-197. DOI: 10.3354/meps12812.

Dillon J, Stevenson RB, Wals AEJ. 2016. Introduction to the special section Moving from Citizen to Civic Science to Address Wicked Conservation Problems. Corrected by erratum 12844. Conservation Biology 30:450-455. DOI: 10.1111/cobi.12689.

Eldridge A, Casey M, Moscoso P, Peck M. 2016. A new method for ecoacoustics? Toward the extraction and evaluation of ecologically-meaningful soundscape components using sparse coding methods. PeerJ 2016. DOI: 10.7717/peerj.2108.

Eldridge A, Guyot P, Moscoso P, Johnston A, Eyre-Walker Y, Peck M. 2018. Sounding out ecoacoustic metrics: Avian species richness is predicted by acoustic indices in temperate but not tropical habitats. Ecological Indicators 95:939-952. DOI: 10.1016/J.ECOLIND.2018.06.012.

Elise S, Bailly A, Urbina-Barreto I, Mou-Tham G, Chiroleu F, Vigliola L, Robbins WD, Bruggemann JH. 2019a. An optimised passive acoustic sampling scheme to discriminate among coral reefs' ecological states. Ecological Indicators 107. DOI: 10.1016/j.ecolind.2019.105627.

Elise S, Urbina-Barreto I, Pinel R, Mahamadaly V, Bureau S, Penin L, Adjeroud M, Kulbicki M, 
543

544

545

546

547

548

549

550

551

552

553

554

555

556

557

558

559

560

561

562

563

564

565

566

567

568

569

570

571

572

573

Bruggemann JH. 2019b. Assessing key ecosystem functions through soundscapes: A new perspective from coral reefs. Ecological Indicators. DOI: 10.1016/j.ecolind.2019.105623.

Elise S, Urbina-Barreto I, Pinel R, Mahamadaly V, Bureau S, Penin L, Adjeroud M, Kulbicki M, Bruggemann JH. 2019c. Assessing key ecosystem functions through soundscapes: A new perspective from coral reefs. Ecological Indicators 107. DOI:

10.1016/j.ecolind.2019.105623.

Elise S, Urbina-Barreto I, Pinel R, Mahamadaly V, Bureau S, Penin L, Adjeroud M, Kulbicki M, Bruggemann JH. 2019d. Assessing key ecosystem functions through soundscapes: A new perspective from coral reefs. Ecological Indicators 107:105623. DOI: 10.1016/j.ecolind.2019.105623.

FAO. 2018. The State of World Fisheries and Aquaculture 2018 - Meeting the sustainable development goals. Rome. Licence: CC BY-NC-SA 3.0 IGO.

Freeman SE, Freeman LA, Giorli G, Haas AF. 2018. Photosynthesis by marine algae produces sound, contributing to the daytime soundscape on coral reefs. PLOS ONE 13:e0201766. DOI: 10.1371/journal.pone.0201766.

Frieler K, Meinshausen M, Golly A, Mengel M, Lebek K, Donner SD, Hoegh-Guldberg O. 2013. Limiting global warming to $2 \mathrm{C}$ is unlikely to save most coral reefs. Nature Climate Change 3:165-170. DOI: $10.1038 /$ nclimate 1674 .

Fukunaga A, Burns JHR, Craig BK, Kosaki RK. 2019. Integrating three-dimensional benthic habitat characterization techniques into ecological monitoring of coral reefs. Journal of Marine Science and Engineering 7. DOI: 10.3390/jmse7020027.

Giyanto, Mumby P, Dhewani N, Abrar M. 2017. Coral Reef health Index of Indonesia. Jakarta: Research Center for Oceanography-LIPI.

Graham NAJ, Nash KL. 2013. The importance of structural complexity in coral reef ecosystems. Coral Reefs 32:315-326. DOI: 10.1007/s00338-012-0984-y.

Graham NAJ, Wilson SK, Pratchett MS, Polunin NVC, Spalding MD. 2009. Coral mortality versus structural collapse as drivers of corallivorous butterflyfish decline. Biodiversity and Conservation 18:3325-3336. DOI: 10.1007/s10531-009-9633-3.

Gratwicke B, Speight MR. 2005. Effects of habitat complexity on Caribbean marine fish assemblages. Marine Ecology Progress Series 292:301-310. DOI: 10.3354/meps292301.

Hernández-Landa RC, Barrera-Falcon E, Rioja-Nieto R. 2020. Size-frequency distribution of 
574

575

576

577

578

579

580

581

582

583

584

585

586

587

588

589

590

591

592

593

594

595

596

597

598

599

600

601

602

603

604

coral assemblages in insular shallow reefs of the Mexican Caribbean using underwater photogrammetry. PeerJ 8:e8957. DOI: 10.7717/peerj.8957.

Hughes TP, Barnes ML, Bellwood DR, Cinner JE, Cumming GS, Jackson JBC, Kleypas J, Van De Leemput IA, Lough JM, Morrison TH, Palumbi SR, Van Nes EH, Scheffer M. 2017. Coral reefs in the Anthropocene. Nature 546:82-90. DOI: 10.1038/nature22901.

Jain-Schlaepfer S, Fakan E, Rummer JL, Simpson SD, McCormick MI. 2018. Impact of motorboats on fish embryos depends on engine type. Conservation Physiology 6. DOI: 10.1093/CONPHYS/COY014.

Kaplan MB, Lammers MO, Zang E, Aran Mooney T. 2018. Acoustic and biological trends on coral reefs off Maui, Hawaii. Coral Reefs 37:121-133. DOI: 10.1007/s00338-017-1638-x.

Kennedy E V., Holderied MW, Mair JM, Guzman HM, Simpson SD. 2010. Spatial patterns in reef-generated noise relate to habitats and communities: Evidence from a Panamanian case study. Journal of Experimental Marine Biology and Ecology 395:85-92. DOI: 10.1016/j.jembe.2010.08.017.

Komyakova V, Munday PL, Jones GP. 2013. Relative importance of coral cover, habitat complexity and diversity in determining the structure of reef fish communities. PLoS ONE 8. DOI: 10.1371/journal.pone.0083178.

Lellouch L, Pavoine S, Jiguet F, Glotin H, Sueur J. 2014. Monitoring temporal change of bird communities with dissimilarity acoustic indices. Methods in Ecology and Evolution 5:495505. DOI: $10.1111 / 2041-210 X .12178$.

Lindseth A, Lobel P. 2018. Underwater Soundscape Monitoring and Fish Bioacoustics: A Review. Fishes 3:36. DOI: 10.3390/fishes3030036.

Lobel PS, Kaatz IN, Rice AN. 2010. Acoustical behavior of reef fishes. In: Cole K ed. Reproduction and sexuality in marine fishes: patterns and processes. Berkeley: University of California Press, 307-385.

Lugli M. 2012. Acoustics of fish shelters: Frequency response and gain properties. The Journal of the Acoustical Society of America 132:3512-3524. DOI: 10.1121/1.4754581.

Mann DA, Lobel PS. 1995. Passive acoustic detection of sounds produced by the damselfish, Dascyllus albisella (Pomacentridae). Bioacoustics 6:199-213. DOI: 10.1080/09524622.1995.9753290.

Obura DO, Aeby G, Amornthammarong N, Appeltans W, Bax N, Bishop J, Brainard RE, Chan 
605

606

607

608

609

610

611

612

613

614

615

616

617

618

619

620

621

622

623

624

625

626

627

628

629

630

631

632

633

634

635 31

S, Fletcher P, Gordon TAC, Gramer L, Gudka M, Halas J, Hendee J, Hodgson G, Huang D, Jankulak M, Jones A, Kimura T, Levy J, Miloslavich P, Chou LM, Muller-Karger F, Osuka K, Samoilys M, Simpson SD, Tun K, Wongbusarakum S. 2019. Coral reef monitoring, reef assessment technologies, and ecosystem-based management. Frontiers in Marine Science 6:580. DOI: $10.3389 /$ fmars.2019.00580.

Patrick Lyon R, Eggleston DB, Bohnenstiehl DWR, Layman CA, Ricci SW, Allgeier JE. 2019.

Fish community structure, habitat complexity, and soundscape characteristics of patch reefs in a tropical, back-reef system. Marine Ecology Progress Series 609:33-48. DOI: 10.3354/meps 12829 .

Pieretti N, Farina A, Morri D. 2011. A new methodology to infer the singing activity of an avian community: The Acoustic Complexity Index (ACI). Ecological Indicators 11:868-873.

DOI: 10.1016/j.ecolind.2010.11.005.

Raoult V, David PA, Dupont SF, Mathewson CP, O’Neill SJ, Powell NN, Williamson JE. 2016. GoPros $^{\mathrm{TM}}$ as an underwater photogrammetry tool for citizen science. PeerJ 4:e1960. DOI: 10.7717/peerj.1960.

RStudio Team. 2015. RStudio: Integrated Development Environment for R.

Ruiz JF, Gonzalez-Correa JM, Bayle-Sempere J, Ramis J, Rountree RA, Juanes F. 2017. Comparison between the marine soundscape of recreational boat mooring areas with that of a pristine area in the Mediterranean: Evidence that such acoustic hot-spots are detrimental to ecologically sensitive habitats. The Journal of the Acoustical Society of America 141:3945-3946. DOI: 10.1121/1.4988951.

Schmiedel U, Araya Y, Bortolotto MI, Boeckenhoff L, Hallwachs W, Janzen D, Kolipaka SS, Novotny V, Palm M, Parfondry M, Smanis A, Toko P. 2016. Contributions of paraecologists and parataxonomists to research, conservation, and social development. Conservation Biology 30:506-519. DOI: 10.1111/cobi.12661.

Simpson S, Yan H, Wittenrich M, Meekan M. 2005. Response of embryonic coral reef fishes (Pomacentridae: Amphiprion spp.) to noise. Marine Ecology Progress Series 287:201-208. DOI: $10.3354 /$ meps 287201.

Staaterman E, Ogburn M, Altieri A, Brandl S, Whippo R, Seemann J, Goodison M, Duffy J. 2017. Bioacoustic measurements complement visual biodiversity surveys: preliminary evidence from four shallow marine habitats. Marine Ecology Progress Series 575:207-215. 
636

637

638

639

640

641

642

643

644

645

646

647

648

649

650

651

652

653

654

655

656

657

658

DOI: $10.3354 /$ meps 12188 .

Storlazzi CD, Dartnell P, Hatcher GA, Gibbs AE. 2016. End of the chain? Rugosity and finescale bathymetry from existing underwater digital imagery using structure-from-motion (SfM) technology. Coral Reefs 35:889-894. DOI: 10.1007/s00338-016-1462-8.

Sueur J. 2018. Sound Analysis and Synthesis with R. Cham: Springer International Publishing. DOI: $10.1007 / 978-3-319-77647-7$.

Sueur J, Aubin T, Simonis C. 2008. Seewave: a free modular tool for sound analysis and synthesis. Bioacoustics 18:213-226.

Tricas TC, Boyle KS. 2014. Acoustic behaviors in Hawaiian coral reef fish communities. Source: Marine Ecology Progress Series 511:1-16. DOI: 10.2307/24894711.

Versluis M, Schmitz B, Von der Heydt A, Lohse D. 2000. How snapping shrimp snap: Through cavitating bubbles. Science 289:2114-2117. DOI: 10.1126/science.289.5487.2114.

Vieira M, Fonseca PJ, Amorim MCP, Teixeira CJC. 2015. Call recognition and individual identification of fish vocalizations based on automatic speech recognition: An example with the Lusitanian toadfish. The Journal of the Acoustical Society of America 138:3941-3950. DOI: $10.1121 / 1.4936858$.

Villanueva-Rivera LJ, Pijanowski BC. 2018. soundecology: Soundscape Ecology.

Villanueva-Rivera LJ, Pijanowski BC, Doucette J, Pekin B. 2011. A primer of acoustic analysis for landscape ecologists. Landscape Ecology 26:1233-1246. DOI: 10.1007/s10980-0119636-9.

Young GC, Dey S, Rogers AD, Exton D. 2017. Cost and time-effective method for multi-scale measures of rugosity, fractal dimension, and vector dispersion from coral reef 3D models. PLOS ONE 12:e175341. DOI: 10.1371/journal.pone.0175341.

659 
Figure 1

The Birds Head Peninsula of West Papua Province, Indonesia, showing locations of sampling sites 


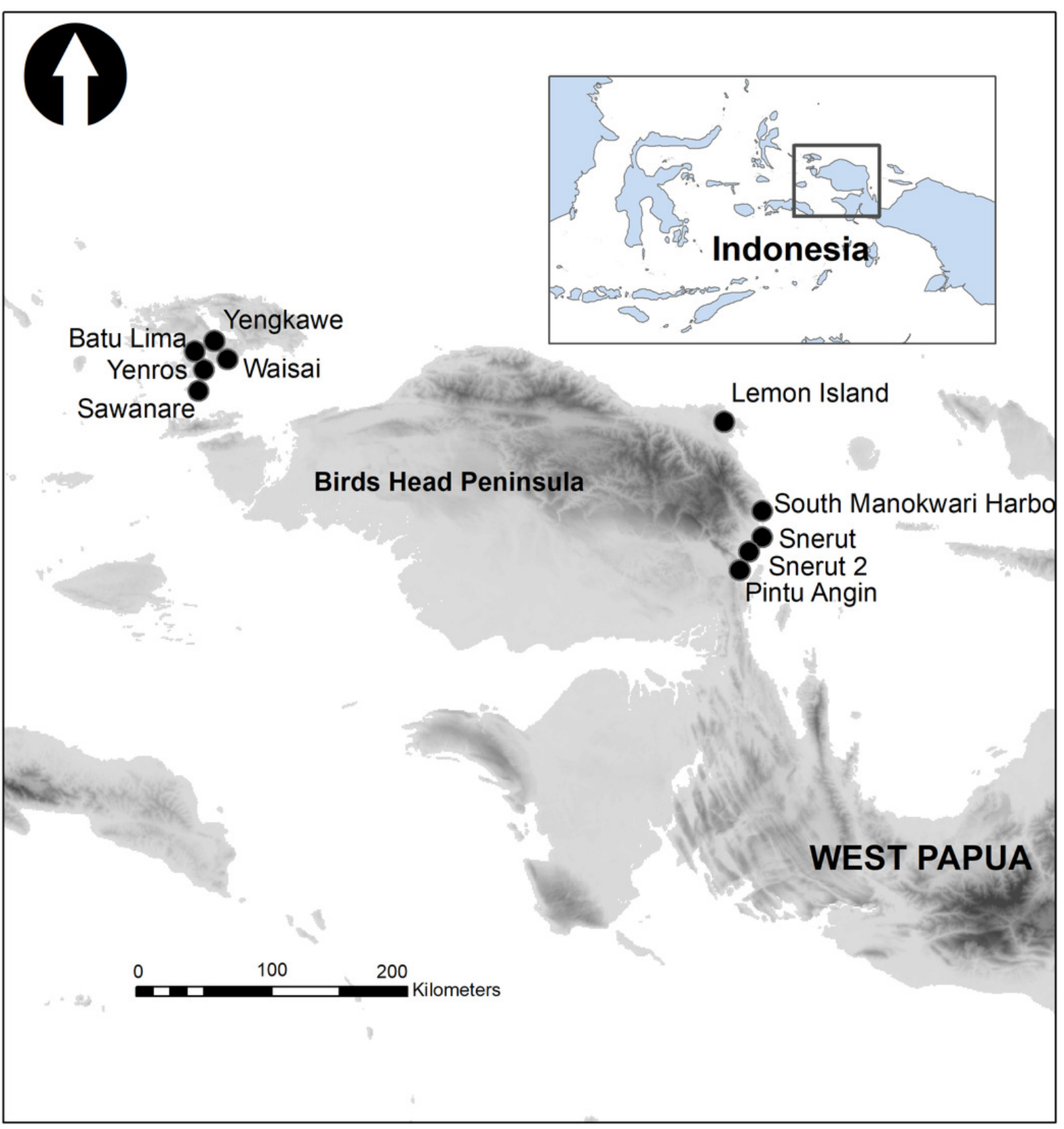


Figure 2

3D model reconstructed from video imagery.

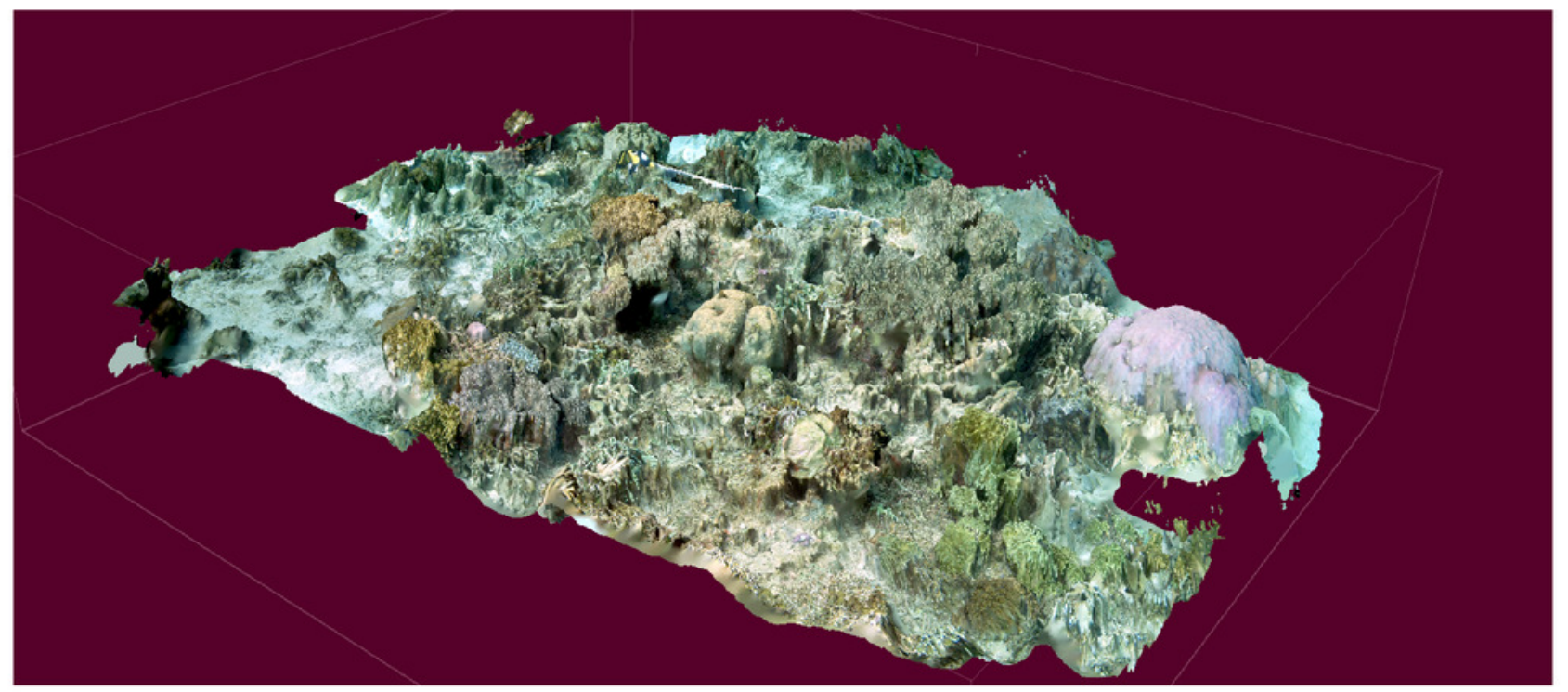


Figure 3

Fish abundance against percentage live coral cover.

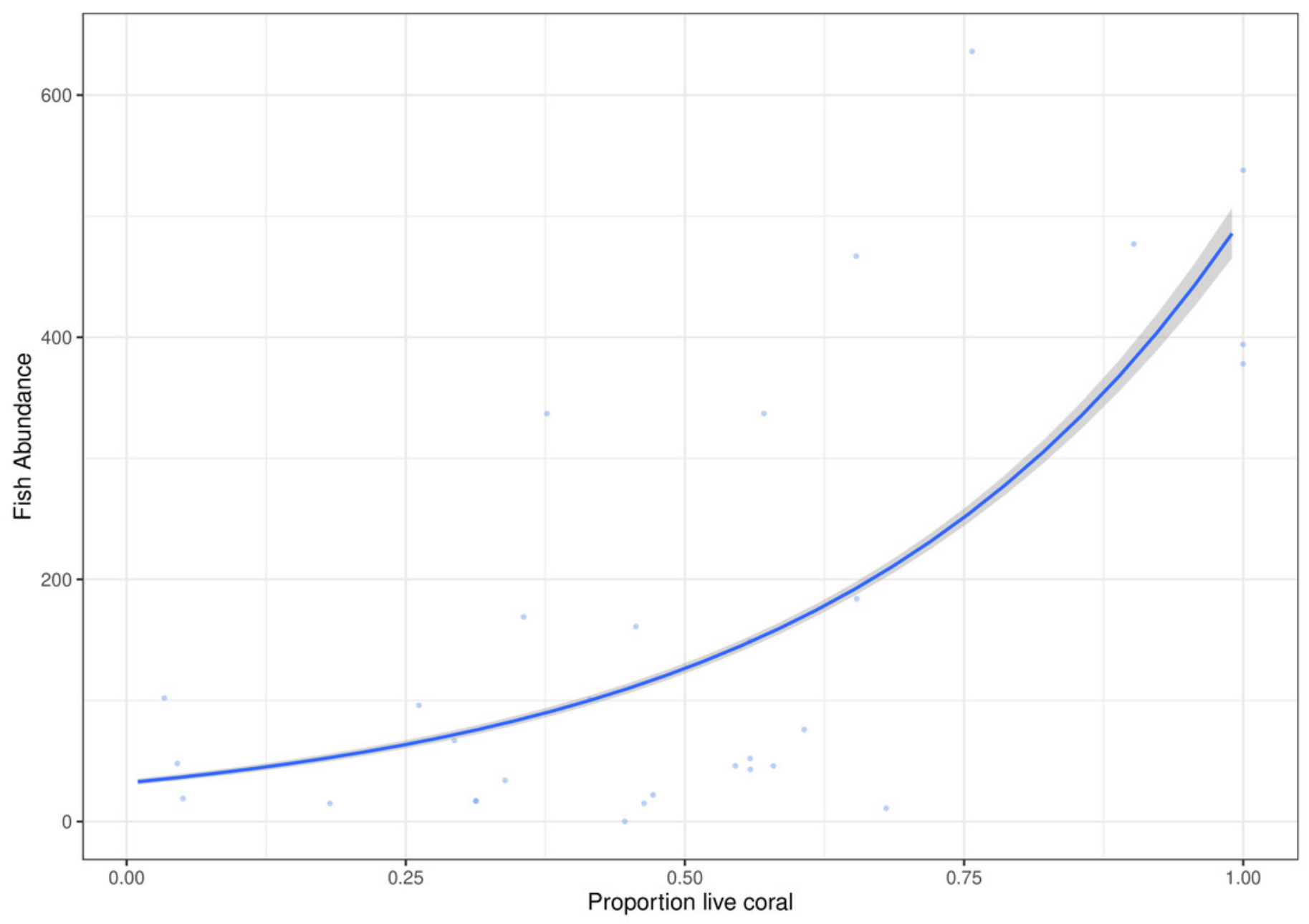


Figure 4

Shorth term temporal stablility of acoustic indices illustrated by correlation coefficient of index across minutes 4-5, 5-6 and 6-7.

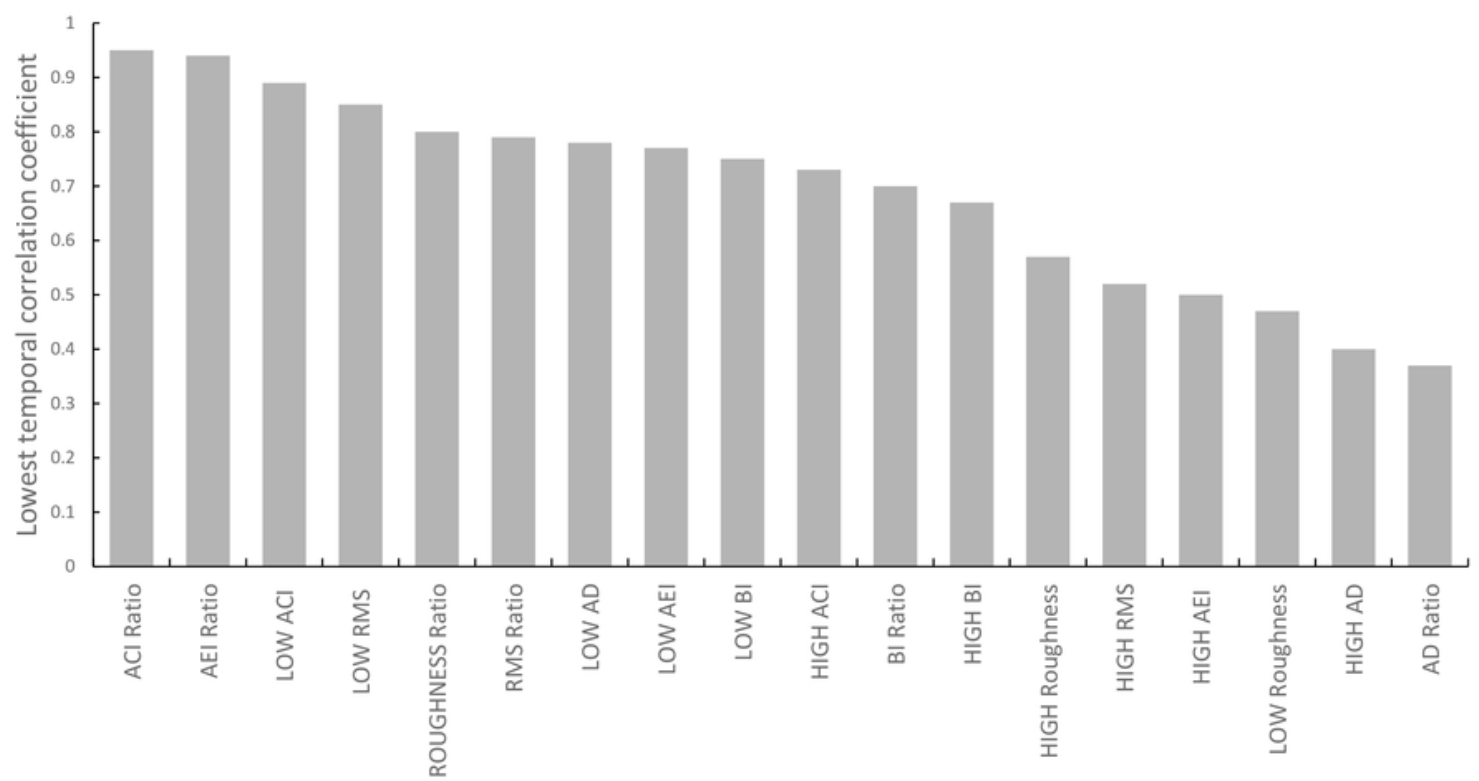

Acoustic Index 
Figure 5

Example spectrograms of lower frequency band $(100 \mathrm{~Hz}$ to $1200 \mathrm{~Hz})$ from replicates representing high (A) and low (B) fish abundance. 

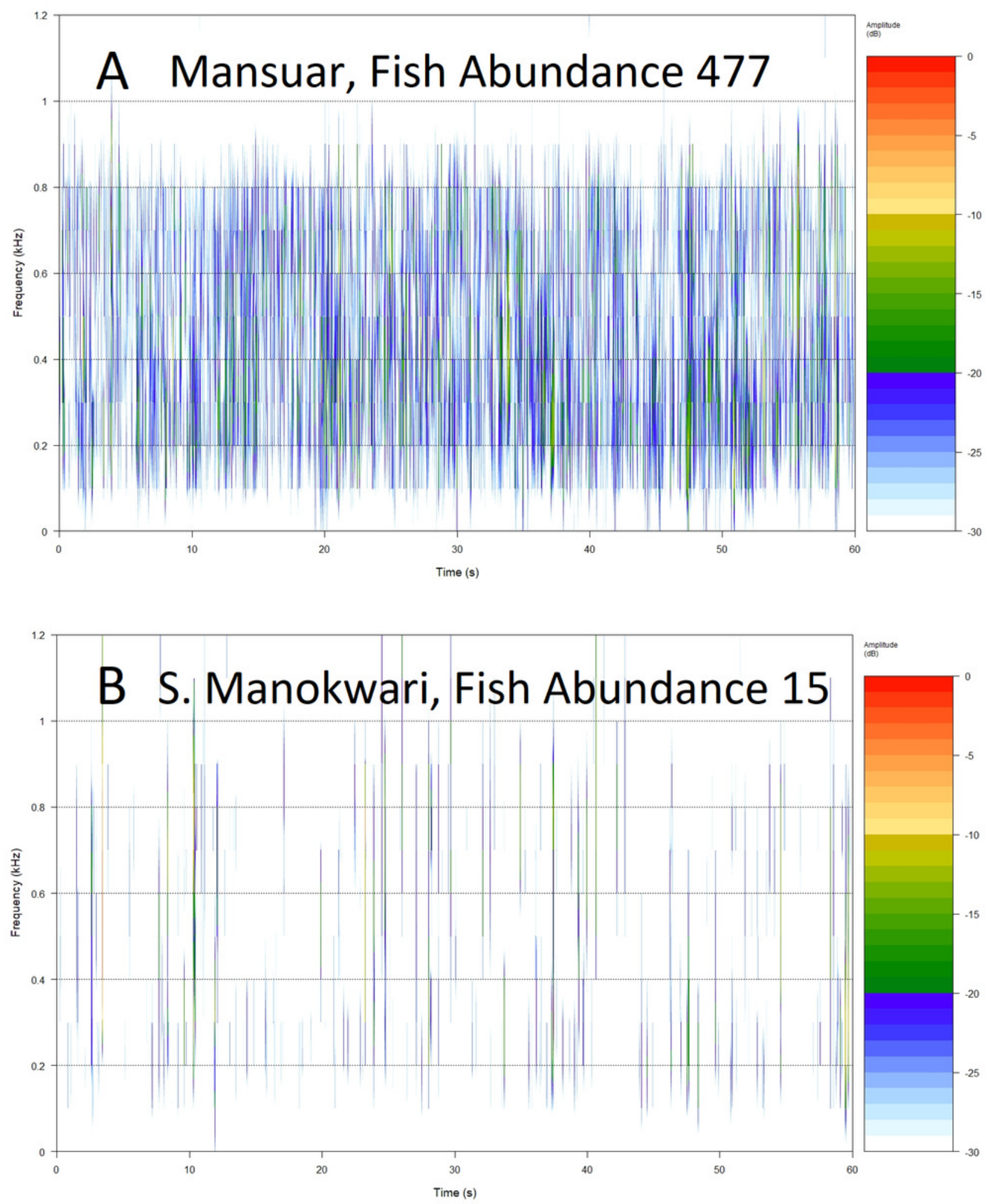
Figure 6

Fish abundance against Acoustic Evenness Index $(1200 \mathrm{~Hz}$ to $11050 \mathrm{~Hz})$.

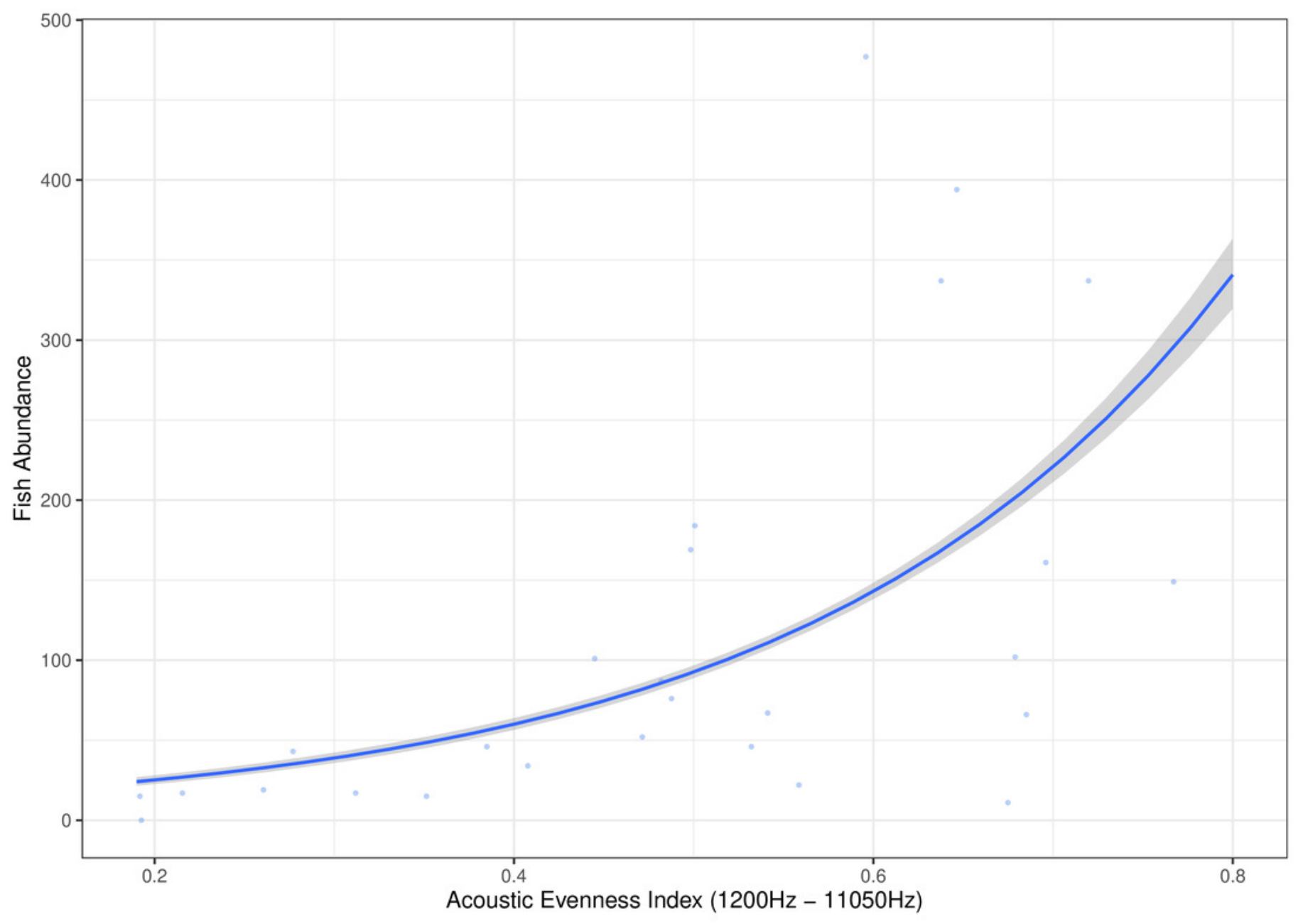




\section{Figure 7}

Correlation plot illustrating deviance explaained by acoustic indices across fish diversity and environmental indicator groups.

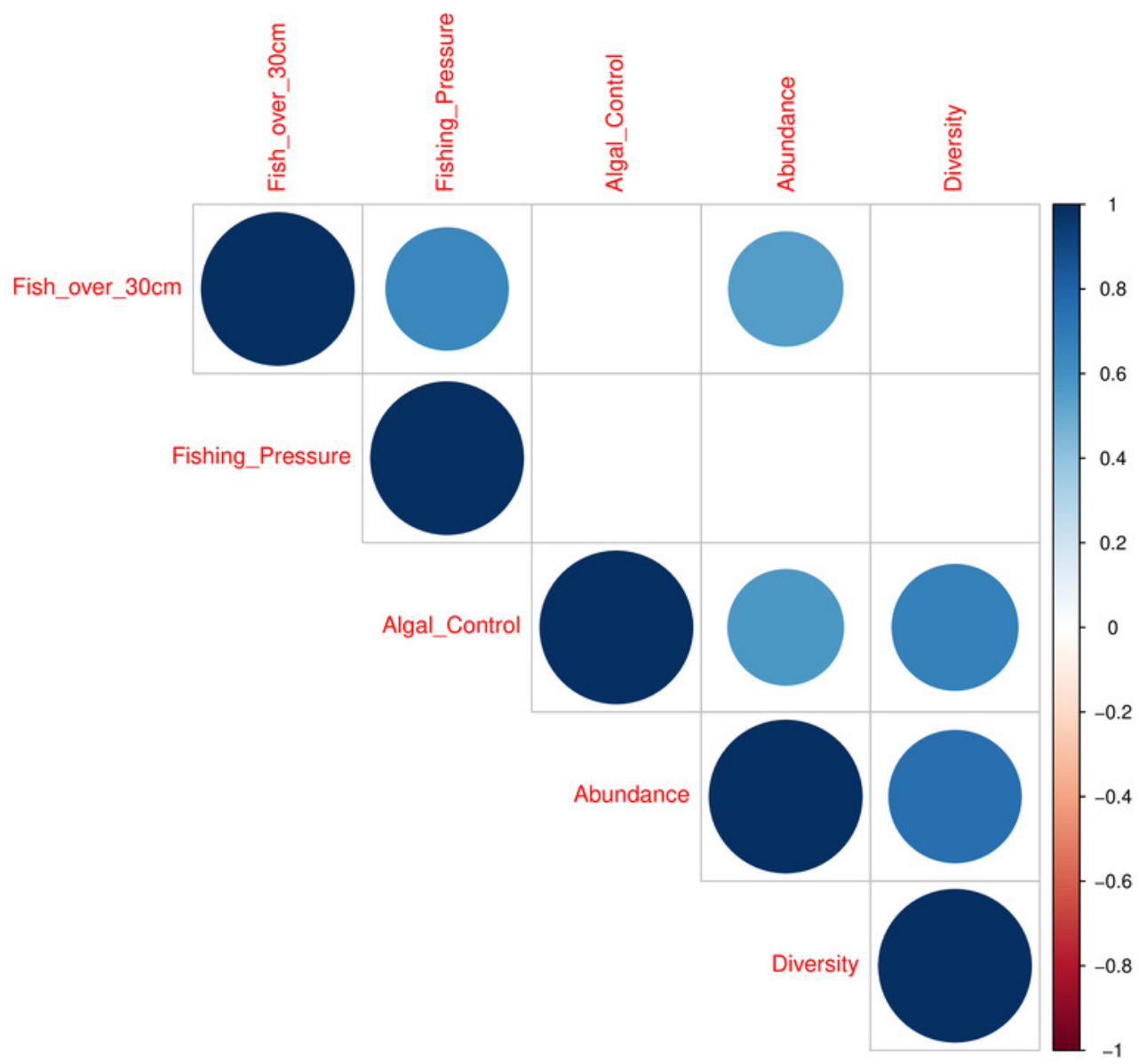




\section{Table $\mathbf{1}$ (on next page)}

Deviance explained by individual acoustic indices for fish diversity and environmental indicator groups 
1 Table 1. Significant deviance explained by individual acoustic indicators in GLM

2 models. Top 3 predictions for acoustic indicators in each fish indicator category

3 highlighted in grey

\begin{tabular}{|c|c|c|c|c|c|c|}
\hline \multirow{2}{*}{$\begin{array}{l}\text { GLM model acoustic } \\
\text { index predictor }\end{array}$} & \multicolumn{6}{|c|}{ Deviance explained for all statistically significant models } \\
\hline & $\begin{array}{l}\text { Fish } \\
\text { Abundance }\end{array}$ & $\begin{array}{l}\text { Fish } \\
>30 \mathrm{~cm} \\
\text { length }\end{array}$ & $\begin{array}{l}\text { Coral health } \\
\text { (Corallivores) }\end{array}$ & $\begin{array}{l}\text { Fishing Pressure } \\
\text { (targeted fish } \\
\text { families) }\end{array}$ & $\begin{array}{l}\text { Algal Control } \\
\text { (Fish algal } \\
\text { control) }\end{array}$ & $\begin{array}{l}\text { Fish } \\
\text { species } \\
\text { diversity }\end{array}$ \\
\hline AEI HIGH & $40.0 \%$ & $11.3 \%$ & $0.0 \%$ & $7.3 \%$ & $21.8 \%$ & $24.1 \%$ \\
\hline AC LOW & $38.4 \%$ & $17.5 \%$ & $0.0 \%$ & $0.0 \%$ & $14.0 \%$ & $10.4 \%$ \\
\hline RMS Ratio & $33.5 \%$ & $13.2 \%$ & $0.0 \%$ & $0.0 \%$ & $20.3 \%$ & $14.0 \%$ \\
\hline AC HIGH & $33.0 \%$ & $25.3 \%$ & $0.0 \%$ & $10.9 \%$ & $8.3 \%$ & $11.3 \%$ \\
\hline AC Ratio & $31.7 \%$ & $8.8 \%$ & $0.0 \%$ & $0.0 \%$ & $14.7 \%$ & $6.6 \%$ \\
\hline AD HIGH & $31.1 \%$ & $6.7 \%$ & $0.0 \%$ & $0.0 \%$ & $17.3 \%$ & $19.4 \%$ \\
\hline BI HIGH & $23.6 \%$ & $13.8 \%$ & $0.0 \%$ & $0.0 \%$ & $7.7 \%$ & $6.3 \%$ \\
\hline AEI Ratio & $23.3 \%$ & $17.8 \%$ & $0.0 \%$ & $6.8 \%$ & $22.9 \%$ & $19.2 \%$ \\
\hline AD Ratio & $22.8 \%$ & $3.7 \%$ & $0.0 \%$ & $0.0 \%$ & $13.2 \%$ & $15.3 \%$ \\
\hline HIGH RMS & $21.2 \%$ & $2.1 \%$ & $0.0 \%$ & $0.0 \%$ & $3.8 \%$ & $5.0 \%$ \\
\hline BI Ratio & $18.7 \%$ & $16.2 \%$ & $0.0 \%$ & $0.0 \%$ & $16.5 \%$ & $4.4 \%$ \\
\hline LOW RMS & $17.7 \%$ & $18.3 \%$ & $0.0 \%$ & $12.0 \%$ & $21.7 \%$ & $6.9 \%$ \\
\hline BI LOW & $8.5 \%$ & $11.4 \%$ & $0.0 \%$ & $0.0 \%$ & $15.3 \%$ & $2.7 \%$ \\
\hline HIGH ROUGHNESS & $6.9 \%$ & $0.0 \%$ & $0.0 \%$ & $0.0 \%$ & $9.7 \%$ & $8.0 \%$ \\
\hline ROUGHNESS Ratio & $2.1 \%$ & $0.0 \%$ & $0.0 \%$ & $0.0 \%$ & $7.6 \%$ & $2.5 \%$ \\
\hline AD LOW & $1.6 \%$ & $7.8 \%$ & $0.0 \%$ & $0.0 \%$ & $4.4 \%$ & $2.1 \%$ \\
\hline LOW ROUGHNESS & $1.3 \%$ & $2.5 \%$ & $0.0 \%$ & $0.0 \%$ & $6.1 \%$ & $0.4 \%$ \\
\hline AEI LOW & $0.2 \%$ & $4.6 \%$ & $0.0 \%$ & $0.0 \%$ & $3.9 \%$ & $0.8 \%$ \\
\hline
\end{tabular}

4 